\title{
Pengaruh Metode Pembelajaran Guided Discovery Terhadap Tingkat Pemahaman Siswa Pada Materi Tarakib di Madrasah Aliyah Mafatihul Huda Cirebon
}

\author{
Utiyani \\ Madrasah Aliyah Mafatihul Huda Cirebon \\ Email: utiyani.cr@yahoo.com \\ Hasan Saefuloh \\ Institut Agama Islam Negeri (IAIN) Syekh Nurjati Cirebon \\ Email: hazansf@yahoo.com
}

\begin{abstract}
This research was conducted in class XI IPA of the Madrasah Aliyah Mafatih alHuda Depok Cirebon. In order to determine the level of students' understanding of the tarakib material. In this case the researchers tasted Guided Discovery Learning Method in tarakib learning. And then analyzed the effect of method based on student test results. The method used in this study is a trial research method with the pre-experiment technique and research design is intact group comparison. In this study there were experimental groups and control groups. And the tools used by researchers in collecting data are through tests. Therefore of the researcher used the " $t$ " test to find out the truth of Ho and Ha. The results in this study were the influence of Guided Discovery Learning Method on the level of students' understanding of tarakib material in the experimental group. This is based on the average value of the experimental group is 79 higher than the control group is 41,2 . And based on the results of a simple regression analysis is $\mathrm{Y}=88,429+1,179 \mathrm{X}$ with a correlation value of 0,606 and the coefficient of determination (R Square) of 0,367 . Through a simple regression analysis using SPSS software produces the Sig. 0,000<0,05 which means that Ho is rejected and $\mathrm{Ha}$ is accepted. It is also strengthened through the $t$-test to test the hypothesis namely to result a value of $t_{\text {count }} 2,745$ and a $t_{\text {table }}$ value of 1,705 . So that $t_{\text {count }}>t_{\text {table }}$ which means Ha is accepted and Ho is rejected.
\end{abstract}

Keywords: Guided Discovery Learning Method, Tarakib Learning, Mafatihul Huda High School

\section{Abstrak}

Penelitian ini dilakukan di kelas XI Madrasah Aliyah Mafatihul Huda Depok Cirebon dengan tujuan untuk mengetahui tingkat pemahaman siswa pada materi tarakib. Dalam hal ini peneliti menguji cobakan metode pembelajaran penemuan terbimbing (Guided Discovery Learning) dalam pembelajaran tarakib, 
yang kemudian menganalisis pengaruh metode tersebut berdasarkan hasil tes siswa. Metode yang digunakan dalam penelitian ini adalah metode penelitian uji coba, dengan teknik Pre-Experiment dan desain penelitiannya adalah Intact Group Comparison. Dalam penelitian ini terdapat kelompok eksperimen dan kelompok kontrol. Dan alat yang digunakan peneliti dalam mengumpulkan data adalah melalui tes. Oleh karena itu peneliti menggunakan uji $\mathrm{t}$ untuk mengetahui kebenaran Ho dan Ha. Hasil dalam penelitian ini adalah adanya pengaruh metode pembelajaran Guided Discovery terhadap tingkat pemahaman siswa pada materi tarakib di kelompok eksperimen. Hal tersebut berdasarkan nilai rata-rata kelompok eksperimen yaitu 79 lebih tinggi dari kelompok kontrol yaitu 41,2. Dan berdasarkan hasil analisis regresi sederhana menghasilkan $\mathrm{Y}=$ $88,429+1,179$ X dengan nilai korelasi sebesar 0,606 dan koefisien determinasi (R-Square) sebesar 0,367. Melalui analisis regresi sederhana dengan menggunakan Software SPSS mengahasilkan nilai Sig. 0,000 <0,05 yang berarti Ho ditolak dan Ha diterima. Dikuatkan juga melalui Uji-t untuk menguji hipotesis yaitu mengahasilkan nilai $t_{\text {hitung }} 2,745$ dan nilai $t_{\text {tabel }}$ 1,705 sehingga $t_{\text {hitung }}>\mathrm{t}_{\text {tabel }}$ yang berarti Ha diterima dan Ho ditolak.

Kata kunci: Metode Guided Discovery Learning, Pembelajaran Tarakib, Madrasah Aliyah Mafatihul Huda

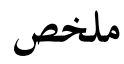

أجري هذا البحث فن الفصل الحادى عشر بمدرسة مفاتيح المدى الثانوية ديبوك شربون بهدف لمعرفة ترقية فهم الطلاب على مادة التراكيب. ف هذا الحال، الباحثة تجرب طريقة التعلم بالاكتشاف الموجه في تعليم التراكيب، ثئّ تحلل تأثير تلك الطريقة على أساس نتيجة اجتبار Pre-experiment الطلاب. وطريقة البحث التي تستخدم الباحثة هي طريقة تجريبية بأسلوبي وبتصميمها هي Intact Group Comparison. فن هذا البحث فصل التجربة وفصل المراقبة. و والآلة التي تستخدم الباحثة في جمع البيانات هي بالإختبار. ولذلك تستخدم الباحثة اختبار "ت" لمعرفة الصدق Ho و Ha. فالنتيجة في هذا البحث هي وجود تأثير طريقة التعلم بالاكتشاف الموجه على ترقية فهم الطلاب على مادة التراكيب فن فصل التجربة. و ذلك على أساس نتيجة معدل في فصل التجربة هي وq أعلى من فصل المراقبة هي r،اءع. وعلى أساس نتيجة تحليل الإنحار الخطي

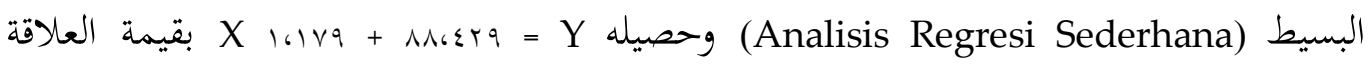
(Korelasi) Analisis Regresi Sederhana 
ومعناه Ho مفروض و Ha مقبول. وهذا اثبت أيضا من حلال اختبار "ت" لإختبار الفرضية هي

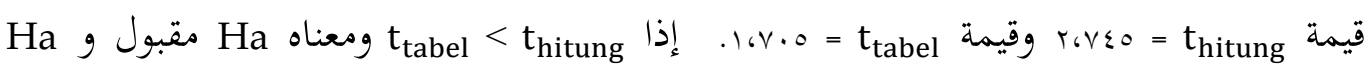
مفروض.

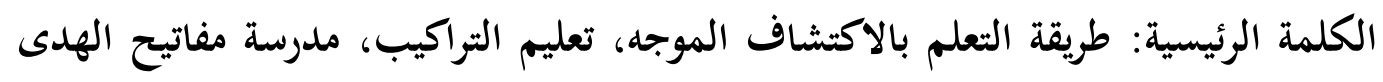
الثانوية

\section{Pendahuluan}

Dalam pembelajaran bahasa Arab, siswa akan diajarkan keterampilan berbahasa (maharat al-istima', maharat al-kalam, maharat alqira'ah dan maharat al-kitabah) dan unsur-unsur bahasa Arab (ashwat, sharaf, nahwu, dalalah dan mufrodat). Salah satu unsur yang terpenting dalam bahasa adalah tata kalimat (sintaksis) atau disebut ilmu nahwu, atau qawa'id, atau tarakib dalam bahasa Arab, karena dalam mempelajari bahasa Arab wajib bagi kita untuk mempelajari dan memahami kaidahkaidahnya. ${ }^{1}$

Mempelajari kaidah-kaidah bahasa merupakan bagian yang terpenting dalam mempelajari bahasa Arab, karena dengan mempelajarinya kita dapat menggunakan bahasa Arab dengan benar yaitu sesuai dengan kaidah. Untuk itu materi tarakib menjadi kebutuhan pokok dalam pembelajaran bahasa Arab. Seperti apa yang diungkapkan oleh Al-Galayainiy bahwa "Ilmu yang terpenting dalam bahasa Arab yaitu ilmu sharaf dan I'rab atau ilmu nahwu".2

Tarakib merupakan salah satu materi yang terdapat dalam mata pelajaran bahasa Arab di setiap Bab. Dengan adanya pembelajaran tarakib, diharapkan siswa dapat menggunakan bahasa Arab dengan baik dan benar. Untuk itu, seorang guru harus memiliki cara bagaimana agar siswa mudah untuk memahami materi yang diajarkan sehingga tujuan pembelajaran tercapai. Peranan guru dalam memberikan kemudahan yakni dengan mengembangkan suasana belajar yang memberikan kesempatan siswa untuk menemukan, menerapkan ide-ide mereka sendiri menjadi sadar dan secara sadar menggunakan strategi mereka

1 'Abdullah Muhammad an-Niqrath, Asy-syaamil Fi Tadris al-Lughah al'Arabiyyah. (Libya: Darul Kutub, 2002). Hal. 7.

2 Musthofa al-Galayainiy, Jaami'u ad-Duruus al-'Arabiyyah. (Mesir: Darul Ma'arif, 1993). Hal. 8. 
sendiri untuk belajar. ${ }^{3}$ Disini berarti muridlah yang menjadi pusat pembelajaran yaitu guru memberi kesempatan kepada siswa untuk lebih aktif.

Berdasarkan hasil observasi dan wawancara yang dilakukan peneliti di Madrasah Aliyah Mafatih al-Huda Kecamatan Depok kota Cirebon yaitu prestasi belajar siswa dalam mata pelajaran bahasa Arab masih rendah yaitu nilai rata-rata 35 , siswa kurang aktif dalam proses belajar - mengajar, siswa mengalami kesulitan dalam memahami materi tarakib. Setelah peneliti mengetahui yang dialami siswa yaitu kesulitan dalam memahami materi tarakib, peneliti melakukan tes tarakib kepada 15 siswa untuk mengetahui kemampuan siswa dalam materi tarakib, dan hasil yang dicapai yaitu dengan nilai rata-rata 19,3 dan nilai tersebut menunjukkan bahwa kemampuan tarakib siswa sangat rendah.

Dalam pembelajaran bahasa Arab, hal yang harus diperhatikan oleh guru bahasa Arab dalam proses belajar mengajar adalah melibatkan peserta didik secara aktif, demokratis, mendidik, memotivasi, mendorong kreativitas, dan dialogis bertujuan agar peserta didik mencapai pola pikir dan kebebasan berpikir, berargumentasi, mengkaji, menemukan dan memprediksi. ${ }^{4}$ Dan sudah menjadi kewajiban bagi guru untuk mewujudkan tujuan pembelajaran yaitu salah satunya dalam menentukan metode pembelajaran yang dapat meningkatkan kemampuan siswa.

Salah satu metode yang pembelajarannya berpusat pada siswa dan menuntut siswa untuk aktif adalah metode pembelajaran Guided Discovery (Penemuan Terbimbing). Pembelajaran guided discovery merupakan suatu modifikasi dari pembelajaran induktif. Pada model ini terdapat ekspose materi kebahasaan terlebih dahulu, kemudian diikuti dengan penggunaan kaidah dan akhirnya secara eksplisit fokus pada aturan kebahasaan dan praktis penggunaannya. ${ }^{5}$ Metode ini memiliki ciri yaitu pembelajaran yang menuntut partisipasi aktif peserta didik, memberikan kebebasan ruang berpikir bagi peserta didik.

3 E. Kosasih, Strategi Belajar dan Pembelajaran Implementasi Kurikulum 2013. (Bandung: Yrama Widya, 2015). Hal. 12.

4 U. H. Saidah, Pengantar Pendidikan : Telaah Pendidikan Secara Global dan Nasional. (Jakarta: Rajawali Pers, 2016). Hal. 22.

5 Vicky Saumell, Guided Discovery for Language Instruction : A Framework for Implementation at all Levels. (Buenos Aires: Person, 2012). Hal. 2. 
Berdasarkan keterangan di atas, penulis tertarik untuk melakukan uji coba metode Guided Discovery (Penemuan Terbimbing) terhadap pembelajaran tarakib, dengan tujuan dapat meningkatkan pemahaman siswa dalam mempelajari materi tarakib, siswa lebih aktif dalam proses pembelejaran tarakib, dan memberi kesempatan siswa untuk berpikir lebih luas.

\section{Metodologi Penelitian}

Metode yang digunakan dalam penelitian ini adalah metode kuantitatif yaitu metode untuk menguji teori-teori tertentu dengan cara meneliti hubungan antar variabel. Dalam penelitian ini terdapat dua variable, (1) variabel bebas (X) yaitu metode pembelajaran Guided Discovery Learning (Penemuan Terbimbing), (2) variabel terikat ( $Y$ ) yaitu pemahaman siswa pada materi tarakib. Adapun jenis penelitian ini adalah penelitian Pre-experiment dengan desain intact group comparison yaitu terdapat kelompok eksperimen dan kelompok kontrol. Dengan tujuan untuk mencari tahu tingkat pemahaman siswa kelas XI MA Mafatih al-Huda setelah pembelajaran, dimana kelompok eksperimen menggunakan metode Guided Discovery Learning, sedangkan kelompok control tidak menggunakan metode Guided Discovery Learning.

Pengumpulan data yang digunakan pada penelitian ini menggunakan tes. Populasi dalam penelitian ini adalah kelas XI IPA yang berjumlah 34 siswa. Sementara sampel yang digunakan adalah seluruh siswa kelas XI IPA, 17 siswa kelompok eksperimen dan 17 siswa kelompok kontrol. Uji validitas dan reliabilitas instrument dilakukan dengan cara expert Judgment dan diuji cobakan di kelas XII IPA dengan bantuan Software SPSS. Selain itu juga pengujian hipotesis dilakukan menggunakan bantuan Software SPSS.

Adapun teknik analisis data yang digunakan antara lain: Deskripsi data meliputi mean, median, dan modus; Uji prasyarat analisis meliputi uji normalitas, uji homogenitas, dan uji linieritas; dan Pengujian hipotesis. Pengujian hipotesis untuk mengetahui ada tidaknya pengaruh metode Guided Discovery terhadap tingkat pemahaman siswa pada materi tarakib. 


\section{Metode Pembelajaran Guided Discovery dalam Pembelajaran Tarakib}

Tarakib adalah aturan-aturan yang mengatur penggunaan bahasa Arab yang digunakan sebagai media untuk memahami kalimat. ${ }^{6}$ Materi tarakib merupakan salah satu materi yang terdapat dalam mata pelajaran bahasa Arab di Sekolah, untuk itu siswa diwajibkan mempelajari materi tarakib (kaidah-kaidah bahasa) supaya siswa dapat menggunakan bahasa Arab dengan baik dan benar, karena pembelajaran tarakib merupakan sebagai pendukung dalam keterampilan berbahasa.

Metode pembelajaran penemuan terbimbing merupakan salah satu macam dari belajar penemuan yaitu salah satu metode pembelajaran induktif yang disebut juga dengan metode ilmiah (Scientific Method) dimana peserta didik belajar secara aktif atau belajar yang berpusat pada peserta didik. Metode guided discovery learning adalah metode pembelajaran yang melibatkan suatu dialog atau interaksi antara siswa dan guru, dimana siswa mencari kesimpulan yang diinginkan melalui suatu urutan pertanyaan yang dilakukan oleh guru. ${ }^{7}$

Metode ini akan melibatkan secara maksimal seluruh kemampuan peserta didik untuk mencari dan menemukan sesuatu secara sistematis, logis, analitis sehingga mereka dapat merumuskan sendiri dalam penemuannya karena dalam metode guided discovery learning siswa akan mendorong siswa untuk berpartisipasi aktif dalam proses belajar mengajar, dapat menumbuhkan sikap inquiry (mencari temukan), dan memberikan wahana iteraksi antar siswa maupun siswa dengan guru.

Salah satu materi yang diajarkan dalam mata pelajaran bahasa Arab adalah materi tarakib yang di dalamnya siswa akan diajarkan tentang nahwu dan sharaf, karena keduanya merupakan kaidah-kaidah bahasa Arab yang harus siswa kuasai. Dalam penelitian ini, materi yang difokuskan adalah materi tarakib pada tema an-nadhofatu fil Islam yaitu tentang idhofah.

Dalam proses pembelajaran tarakib kita dapat melalui metode qiyasiyyah (deduktif) dan metode istiqraiy (induktif) agar tujuan

6 Syaiful Mustofa, Strategi Pembelajaran Bahasa Arab Inovatif. (Malang: UIN Maliki Press, 2011). Hal. 93.

7 Markaban, Metodologi Penemuan Terbimbing pada Pembelajaran MTK. (Yogyakarta: Depdiknas, 2008). Hal. 11. 
pembelajaran tercapai. Tujuan mempelajari tarakib adalah sebagai sarana untuk mendukung kemahiran berbahasa (mendengar, membaca, berbicara, dan menulis), dan agar siswa bisa memahami makna teks bahasa Arab dengan baik dan benar.

Pencapaian suatu keberhasilan dalam pembelajaran bahasa Arab khususnya pembelajaran tarakib, guru harus mampu memilih metode yang tepat untuk memudahkan siswanya dalam memahami materi serta dapat mendorong siswa untuk berpartisipasi aktif. Salah satu metode yang dapat digunakan oleh guru adalah metode guided discovery learning, karena metode ini dianggap sejalan dengan teori pembelajaran bahasa yang lebih modern karena ia mendukung kemandirian sekaligus keterlibatan aktif siswa, serta mendukung pengembangan keterampilan berpikir kritis, serta prinsip-prinsip dasar pembelajaran discovery dapat juga diimplementasikan dalam pembelajaran bahasa Arab dan pembelajaran guided discovery biasanya dihubungkan dengan aturan yang terkait tata bahasa. ${ }^{8}$

Langkah-langkah pembelajaran guided discovery dalam pembelajaran tarakib atau tata bahasa: ${ }^{9}$

a. Pemajanan atau ekspose bahasa melalui contoh atau ilustrasi.

Guru memajankan bahasa kepada para siswa melalui ilustrasi, contoh-contoh, atau kombinasi antara keduanya. Contoh dapat disajikan dalam wujud kalimat lepas. Langkah ini memungkinkan pelajar untuk mengaktifkan strategi belajar personal mereka dalam rangka memahami bahasa yang sedang diekspose kepada mereka.

b. Pengamatan dan analisis bahasa melalui pertanyaan pemandu.

Guru memandu pengamatan dan analisa bahasa dengan menarik perhatian pada poin-poin penting yang ingin disajikan. Ini bisa dilakukan melalui pertanyaan, dengan mengisi bagian yang kosong dari suatu kalimat atau dengan mencocokkan antara contoh dan kaidah. Dalam langkah ini, potensi kognitif siswa ikut serta dilibatkan dalam kerja sama, menelti, membuat hipotesa,

8 Erta Mahyudin, Model Pembelajaran Discovery Sebagai Strategi Pebelajaran Bahasa Arab dalam Arabiyat: Jurnal Pendidikan Bahasa Arab dan Kebahasaaraban, Vol. 1 No. 2 December 2014. Hal. 206.

9 Erta Mahyudin, Model Pembelajaran Discovery Sebagai Strategi Pebelajaran Bahasa Arab.... Hal : 204 
membandingkan, serta membangun dan menyusun pengetahuan baru.

c. Penyusunan atau perumusan kaidah aturan kebahasaan.

Guru menggunakan informasi dari langkah ke dua untuk membuat atau mengarahkan pelajar untuk mengemukakan rumusan mereka tentang kaidah yang sedang mereka pelajari. Pada tahap ini, para pelajar membangun pengetahuan baru mereka sendiri berdasarkan pemahaman pribadinya yang mendalam, pengamatannya, dan analisis yang telah mereka lakukan pada langkah sebelumnya.

d. Aplikasi kaidah dalam tugas praktik yang dijenjangkan berdasarkan tingkat kesukaran atau kompleksitasnya.

Langkah ini bertujuan untuk memposisikan bahasa ke dalam praktik. Guru memberikan beberapa tugas mulai dari bentuk latihan ayang terkontrol sampai ke bentuk latihan yang lebih komunikatif dan penuh arti.

\section{Hasil Penelitian}

\section{Kemampuan siswa kelas kontrol}

Tabel 1

Hasil Post-Test Kelompok Kontrol

\begin{tabular}{|c|l|c|}
\hline No & \multicolumn{1}{|c|}{ Nama Siswa } & Nilai \\
\hline 1 & Ahmad Zamzami & 40 \\
\hline 2 & Steven G & 30 \\
\hline 3 & Muhamad Anwar & 50 \\
\hline 4 & Cicih Nawati & 50 \\
\hline 5 & Kiki Badila & 50 \\
\hline 6 & Lastri Purnamasari & 40 \\
\hline 7 & Asiyah Nurfauziah & 30 \\
\hline 8 & Annisa & 60 \\
\hline 9 & Nurlaelah & 35 \\
\hline 10 & Putri Lestari & 25 \\
\hline 11 & Finadine Nafsah Tsabita & 55 \\
\hline 12 & Adam Maulana & 50 \\
\hline 13 & Alfiyah Nur Karimah & $\mathbf{2 5}$ \\
\hline \multicolumn{2}{|c|}{ Rata-rata } & $\mathbf{4 1 , 2}$ \\
\hline
\end{tabular}


Tabel di atas merupakan hasil tes tarakib siswa kelompok kontrol yang tidak menggunakan metode pembelajaran Guided Discovery Learning yaitu tes yang dilakukan peneliti terhadap 13 siswa dan informasi yang diperoleh dari hasil tes di atas adalah bahwa seluruh siswa kelompok kontrol belum mencapai nilai KKM, dengan nilai ratarata yang dicapai adalah sebesar 41,2 dan jika diporsenkan 100\% siswa tidak mencapai nilai KKM. Ini artinya siswa kelompok kontrol belum memahami materi tarakib (Idhofah) dengan baik.

Kemampuan Siswa Kelompok Eksperimen

Tabel 2

Hasil Post-Test Kelompok Eksperimen

\begin{tabular}{|c|l|c|}
\hline No & \multicolumn{1}{|c|}{ Nama Siswa } & Nilai \\
\hline 1 & Siti Nur Ajijah & 90 \\
\hline 2 & Mukhamad Cholid & 90 \\
\hline 3 & Putri Mar'atin Faizah & 90 \\
\hline 4 & Tri Bayu Krisna Pati & 70 \\
\hline 5 & Muhamad Labik Nurjaya & 85 \\
\hline 6 & Oom Komariyah & 85 \\
\hline 7 & Sri Rahmawati & 80 \\
\hline 8 & Dede Ibnu Muhammad & 80 \\
\hline 9 & Siti Haniyah & 65 \\
\hline 10 & Susilawati & 85 \\
\hline 11 & Ratna Sari & 65 \\
\hline 12 & Veri Fernando & 75 \\
\hline 13 & Sri Yunani & 75 \\
\hline 14 & Yogi & 80 \\
\hline 15 & Muhamad Yusuf & 70 \\
\hline \multicolumn{2}{|c|}{ Rata-rata } & 79 \\
\hline
\end{tabular}

Tabel di atas merupakan hasil tes tarakib siswa kelompok eksperimen yang menggunakan metode pembelajaran Guided Discovery Learning yaitu tes yang dilakukan peneliti terhadap 15 siswa dan informasi yang diperoleh dari hasil tes di atas adalah bahwa banyak siswa kelompok eksperimen yang mencapai nilai KKM, dengan nilai rata-rata yang dicapai adalah sebesar 79 dan jika diporsenkan maka 60\% siswa yang mencapai nilai KKM dan $40 \%$ siswa yang belum mencapai 
nilai KKM. Ini artinya siswa kelompok kontrol telah memahami materi tarakib (Idhofah) dengan cukup baik.

\section{Analisis Penelitian}

\section{a. Uji Normalitas}

Uji normalitas yang digunakan dalam penelitia ini adalah uji one sample Kolmogorov-Smirnov dengan menggunakan taraf signifikasi 0.05 . Data dinyatakan berdistribusi normal jika signifikasi lebih besar dari $5 \%$ atau 0.05 .

\section{Tabel 3}

Uji Normalitas

One-Sample Kolmogorov-Smirnov Test

\begin{tabular}{|ll|r|}
\hline & & \multicolumn{1}{|c|}{ nilai } \\
\hline $\mathrm{N}$ & Mean & 28 \\
& 61.6071 \\
Normal Parametersa,b & Std. & 21.51888 \\
& Deviation & \\
Most Extreme & Absolute & .126 \\
Differences & Positive & .098 \\
& Negative & -.126 \\
Kolmogorov-Smirnov Z & .667 \\
Asymp. Sig. (2-tailed) & .766 \\
\hline
\end{tabular}

a. Test distribution is Normal.

b. Calculated from data.

Dari table One Sample Kolmogorov-Smirnov diperoleh angka probabilitas atau Asymp-Sig (2-tailed). Nilai ini dibandingkan dengan 0.05 atau menggunakan taraf signifikasi 5\%.

Tabel 4

Keputusan Uji Normalitas Data

\begin{tabular}{|c|c|c|c|}
\hline Nama Variabel & $\begin{array}{c}\text { Nilai Asymp- } \\
\text { Sig (2-tailed) }\end{array}$ & $\begin{array}{c}\text { Taraf } \\
\text { Signifikasi }\end{array}$ & Keputusan \\
\hline $\begin{array}{c}\text { Tingkat } \\
\text { Pemahaman } \\
\text { Tarakib }\end{array}$ & 0.766 & 0.05 & Normal \\
\hline
\end{tabular}

(Sumber : Tabel 4.3) 


\section{b. Uji Homogenitas}

Sebagai kriteria pengujian, jika nilai signifikan lebih dari 0.05 maka dapat dikatakan bahwa varian dari dua atau lebih kelompok data adalah sama.

\section{Tabel 5}

\section{Uji Homogenitas}

Test of Homogeneity of Variances

\begin{tabular}{|c|r|r|r|}
\hline $\begin{array}{c}\text { Levene } \\
\text { Statistic }\end{array}$ & df1 & df2 & Sig. \\
\hline 2.485 & 1 & 26 & .127 \\
\hline
\end{tabular}

Dari hasil statistik dari output SPSS di atas diketahui nilai signifikan sebesar 0.127, karena nilai signifikan lebih dari 0.05 maka dapat disimpulkan bahwa kedua kelompok data mempunyai tingkat varians sama.

\section{c. Uji Linieritas}

Uji linieritas dilakukan dengan pengujian pada SPSS dengan menggunakan Curve Estimation. Dua variabel dikatakan mempunyai hubungan yang linier bila signifikansi kurang dari 0.05.

Tabel 6

\section{Uji Linieritas}

ANOVA

\begin{tabular}{|c|c|c|c|c|c|}
\hline & $\begin{array}{c}\text { Sum of } \\
\text { Squares }\end{array}$ & $\mathrm{df}$ & $\begin{array}{c}\text { Mean } \\
\text { Square }\end{array}$ & $\mathrm{F}$ & Sig. \\
\hline $\begin{array}{c}\text { Regressio } \\
\mathrm{n}\end{array}$ & 388.929 & 1 & 388.929 & 7.534 & .017 \\
Residual & 671.071 & 13 & 51.621 & & \\
Total & 1060.000 & 14 & & & \\
\hline
\end{tabular}

Dari tabel output di atas, diperoleh nilai signifikansi $=0.017$ lebih kecil dari 0.05. Karena signifikansi kurang dari 0.05 maka dapat disimpulkan bahwa antara variabel terdapat hubungan linier secara signifikan. 


\section{Uji Hipotesis}

\section{a. Regresi Linier Sederhana}

\section{Tabel 7}

Koefisien

\section{Model Summary}

\begin{tabular}{|c|r|r|r|}
\hline $\mathrm{R}$ & $\begin{array}{c}\mathrm{R} \\
\text { Square }\end{array}$ & $\begin{array}{c}\text { Adjusted } \mathrm{R} \\
\text { Square }\end{array}$ & $\begin{array}{c}\text { Std. Error of } \\
\text { the Estimate }\end{array}$ \\
\hline .606 & .367 & .318 & 7.185 \\
\hline
\end{tabular}

Pada tabel di atas nilai korelasi adalah 0.606. Nilai ini dapat diinterpretasikan bahwa hubungan kedua variabel penelitian berada pada kategori cukup. Melalui tabel di atas juga diperoleh nilai $\mathrm{R}$ Square atau Koefisien Determinasi (KD) yang menunjukkan seberapa bagus model regresi yang dibentuk oleh interaksi variabel bebas dan variabel terikat. Nilai KD yang diperoleh adalah 36,7\%. Sehingga dapat ditafsirkan bahwa variabel bebas $X$ memiliki pengaruh kontribusi sebesar 36,7\% terhadap variabel Y.

\section{Tabel 8}

\section{Uji Nilai Signifikan}

ANOVA

\begin{tabular}{|l|r|r|r|r|r|}
\hline & \multicolumn{1}{|c|}{$\begin{array}{c}\text { Sum of } \\
\text { Squares }\end{array}$} & \multicolumn{1}{c|}{ df } & $\begin{array}{c}\text { Mean } \\
\text { Square }\end{array}$ & F & Sig. \\
\hline Regressio & 388.929 & 1 & 388.929 & 7.534 & .017 \\
$\mathrm{n}$ & 671.071 & 13 & 51.621 & & \\
Residual & 1060.000 & 14 & & & \\
Total & & & & \\
\hline
\end{tabular}

Berdasarkan tabel di atas diperoleh nilai Sig. $=0.017$ berarti Sig. < dari criteria signifikasi (0.05). Dengan demikian model persamaan regresi berdasarkan data penelitian adalah signifikan atau model persamaan regresi memenuhi kriteria. 
Tabel 9

Koefisien Regresi Sederhana

Coefficients

\begin{tabular}{|c|c|c|c|c|c|}
\hline & \multicolumn{2}{|c|}{$\begin{array}{c}\text { Unstandardized } \\
\text { Coefficients }\end{array}$} & $\begin{array}{c}\text { Standardized } \\
\text { Coefficients }\end{array}$ & \multirow{2}{*}{$\mathrm{t}$} & Sig. \\
\cline { 2 - 4 } & $\mathrm{B}$ & Std. Error & Beta & & \\
\hline Y & -1.179 & .429 & -.606 & -2.745 & .017 \\
(Constant) & 88.429 & 3.904 & & 22.651 & .000 \\
\hline
\end{tabular}

Uji kelinieran, nilai Sig $(0.017)<\alpha(0.05)$ sehingga Ho ditolak, jadi model linier signifikan. Uji konstanta dan koefisien, koefisien $b$ memiliki nilai Sig $(0.017)<\alpha$ dan konstanta a memiliki nilai Sig $(0.000)$ $<\alpha$ sehingga Ho ditolak. Jadi, baik konstanta a maupun koefisien $b$ adalah signifikan. Tingkat kepercayaan yang dipakai 0.95 atau $\alpha=$ 0.05. Dan hasil penghitungan koefisien regresi sederhana di atas menunjukkan nilai koefisien konstanta adalah sebesar 88.429 dan koefisien variabel bebas $(X)$ adalah -1.179. Sehingga diperoleh persamaan regresi $\mathrm{Y}=88.429+(-1.179) \mathrm{X}$.

b. Uji t

Tabel 10

Uji Hipotesis

Coefficients

\begin{tabular}{|c|c|c|c|c|c|}
\hline & \multicolumn{2}{|c|}{$\begin{array}{c}\text { Unstandardized } \\
\text { Coefficients }\end{array}$} & $\begin{array}{c}\text { Standardized } \\
\text { Coefficients }\end{array}$ & \multirow{2}{*}{ Sig. } \\
\cline { 2 - 4 } & $\mathrm{B}$ & Std. Error & Beta & & \\
\hline siswa & -1.179 & .429 & -.606 & -2.745 & .017 \\
(Constant) & 88.429 & 3.904 & & 22.651 & .000 \\
\hline
\end{tabular}

a) Perumusan Hipotesis

Ha : Ada pengaruh penggunaan metode pembelajaran guided discovery terhadap pemahaman siswa dalam materi tarakib di kelas XI.

Ho : Tidak Ada pengaruh penggunaan metode pembelajaran guided discovery terhadap pemahaman siswa dalam materi tarakib di kelas XI.

b) Penetapan Kriteria 
Besarnya nilai $t$ tabel untuk taraf signifikan $5 \% \mathrm{db}=26(\mathrm{db}=\mathrm{N}-2$ untuk $\mathrm{N}=28$ ) yaitu 1.705 .

c) Hasil $t$ hitung

Hasil $t$ hitung diperoleh dengan menggunakan SPSS yaitu sebesar 2.745 .

d) Pengambilan keputusan

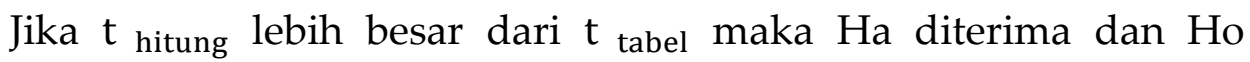
ditolak. Dari hasil perhitungan $\mathrm{t}$ hitung sebesar 2.745 diatas dibandingkan dengan $\mathrm{t}$ tabel $(\mathrm{db}=26)$ yaitu 1.705 taraf signifikan

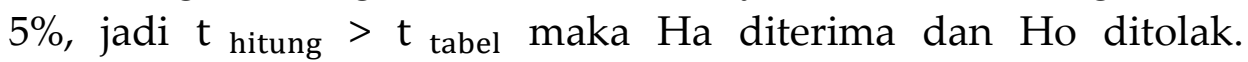
Dengan kata laian menolak hipotesis nol (Ho) dan menerima hipotesis alternatif (Ha) untuk pengujian kedua variabel.

\section{Kesimpulan}

Tingkat pemahaman siswa pada materi tarakib (idhofah) di kelas kontrol rendah, dibuktikan dengan pencapaian nilai rata-rata yang diperoleh yaitu 41,2 dan jika diporsenkan maka 100\% siswa belum mencapai nilai KKM. Tingkat pemahaman siswa pada materi tarakib (idhofah) di kelas eksperimen cukup tinggi, hal ini dibuktikan dengan pencapaian nilai rata-rata 79 dan jika diporsenkan maka 60\% siswa yang mencapai nilai KKM dan 40\% siswa yang belum mencapai KKM.

Penggunaan metode guided discovery learning mempengaruhi terhadap tingkat pemahaman siswa pada materi tarakib (idhofah). Hal ini dibuktikan melalui analisis regresi sederhana dengan bantuan aplikasi SPSS yang menghasilkan nilai Sig. 0,000 < 0,05 jadi Ho ditolak dan Ha diterima. Dikuatkan juga melalui uji " $\mathrm{t}$ ", yang hasilnya adalah hasil perhitungan $t$ hitung sebesar 2.745 diatas dibandingkan dengan $\mathrm{t}$ tabel $(\mathrm{db}=26)$ yaitu 1.705 taraf signifikan $5 \%$, jadi $\mathrm{t}$ hitung $>\mathrm{t}$ tabel maka Ha diterima dan Ho ditolak. Sehingga dapat disimpulkan bahwa variabel $X$ terdapat pengaruh yang signifikan terhadap variabel $Y$. Dari hasil pengujian hipotesis tersebut terbukti bahwa "Ada pengaruh penggunaan metode pembelajaran guided discovery terhadap pemahaman siswa dalam materi tarakib di kelas XI".

\section{Daftar Pustaka}


Al-Galayainiy, Syaikh Musthofa. 1993. Jami'u ad-Duruus al-'Arabiyyah. Mesir : Darul Ma'arif.

An-Niqrath, 'Abdullah Muhammad. 2002. As-saamil fi al-Lughah al'Arabiyyah. Libya : Darul Kutub.

Kosasih, E. 2014. Strategi Belajar dan Pembelajaran (Implementasi Kurikulum 2013). Bandung : Yrama Widya.

Jurnal Arabiyat. Edisi 1 Hal 197-208.

Saidah, U.H. 2016. Pengantar Pendidikan : Telaah Pendidikan Secara Global dan Nasional. Jakarta : Rajawali Pers.

Markaban. 2008. Metodologi Penemuan Terbimbing pada Pembelajaran MTK. Yogyakarta : Depdiknas.

Saumell, Vicky. 2012. Guided Discovery for Language Instruction : A Framework for Implementation at all Levels. Buenos Aires : Person.

Mustofa, Syaiful. 2011. Strategi Pembelajaran Bahasa Arab Inovatif. Malang : UIN-Maliki Press. 